\title{
Heat Transfer by a Briefcase-shaped Air Cooler Using Thermoelectric Cooling Technology: A Case Study
}

\author{
Abu Raihan Mohammad Siddique ${ }^{1 *}$, Syed Tabeeb Wasit Bin Hasan ${ }^{1}$, Mohammad Reza Mohaghegh ${ }^{1}$, \\ Shaikh Hasibul Majid ${ }^{2}$, Shohel Mahmud ${ }^{1}$ \\ ${ }^{1}$ School of Engineering, University of Guelph \\ Guelph, Ontario, Canada \\ 1*asiddi04@uoguelph.ca \\ ${ }^{2}$ Department of Electrical Engineering, University of Tabuk, \\ Saudi Arabia, skhasib@hotmail.com
}

\begin{abstract}
In this paper, a unique briefcase-shaped air cooler has been proposed. Since the thermoelectric cooler is becoming one of the promising alternatives to a typical refrigeration system; therefore, thermoelectric cooling technology has been considered for the proposed air cooler system. In this work, a detailed experimental work has been demonstrated including COP calculation and uncertainty calculation. The experimental results show that the 6-channel heat exchanger is a good fit for the proposed air cooler which reduces the air temperature around $1.5^{\circ} \mathrm{C}$ more compared to the 10 -channel heat exchanger, due to its higher contact surface area for heat exchange. The proposed system has been also tested using two different sizes of the prototype room. It is noticed that the temperature drops $5^{\circ} \mathrm{C}$ from ambient temperature inside the small room while it keeps the room temperature the same at around $22.5^{\circ} \mathrm{C}$ when using a $100 \mathrm{~W}$ heat source inside the room. Furthermore, room temperature comes down at $20{ }^{\circ} \mathrm{C}$ and remains the same as ambient temperature with and without additional heat source due to better heat dissipation in a larger area. The calculated coefficient of performance of the proposed system is 0.3 using only $365 \mathrm{~W}$ electrical power input.
\end{abstract}

Keywords: Air cooling system; thermoelectric cooling; coefficient of performance; heat source.

\section{Introduction}

Energy crises and global warming are becoming more and more serious every day. With consumption being on the alltime high, people are starting to look at more energy-efficient ways of living their lives such as getting electric cars and more efficient/energy saving methods, in turn, implementing it around their house, work and all social places. The power shortage 'epidemic' has become one of the major concerns by the vast majority of people who have addressed their anger towards the world eating away at resources without any plan for the future. With air conditioning being one of the main contributors to excessive fossil fuel usage over the years, people are starting to look at better alternatives for air conditioning hence forcing engineers to come up with more options for air conditioning.

Thermoelectric (TE) systems are mainly used for refrigeration systems and it uses almost no mechanically moving parts and hence can be built into several compact designs to function. Almost $20 \%$ of the energy used by cooling systems goes into the compressor of the systems to keep their refrigerants working in both refrigeration and air conditioning systems [1]. The refrigerants used to consist of many harmful Chlorofluorocarbons (CFCs), Hydrochlorofluorocarbons (HCFCs) and Hydrofluorocarbons (HFCs) which attribute themselves to being a major part of Global warming especially the CFCs/Freon particles. However, the thermoelectric coolers (TEC) usually use an outside source of air to become the cooling agent since they can only produce a hot and a cold side due to the Peltier effect. The advantages of a TEC air conditioning system is that it is quite light in weight and compact in size along with having low levels of noise and vibration in contrast to other air conditioning units, it also has no mechanical moving parts. Moreover, it can be powered by DC power sources. One of its disadvantages would be that it has low energy efficiency compared to its high cost [2].

Several experiments with TEC modules have been carried out by researchers. Pasut et. al., [3] focused more on a single individual than trying to cool an entire room. They incorporated their cooling system into a chair where you can regulate the conditions due to a heating element where you sit and a fan to cool your back according to your needs. Three different conditions were used for three different tests on 23 individuals at $16{ }^{\circ} \mathrm{C}, 18{ }^{\circ} \mathrm{C}$ and $29{ }^{\circ} \mathrm{C}$, A long test of 135 minutes and a short test of 100 minutes which concluded that $90 \%$ of people find comfort around $18^{\circ} \mathrm{C}$ to $29^{\circ} \mathrm{C}$ and only 
$75 \%$ at around $16^{\circ} \mathrm{C}$ [3]. Irshad et. al., [4] developed a TE module in a Malaysian tropical environment using a duct connected to a room with 20 individuals. The TEM's operate from $2 \mathrm{~A}$ to $7 \mathrm{~A}$ and they checked for temperatures from around $10 \mathrm{AM}$ to $6 \mathrm{PM}$. The room temperatures would go from warm to comfortable/neutral from 2A to 5A [4].

In addition, Alomair et. al., [5] developed a solar thermoelectric liquid cooler that uses solar energy to cool down warm liquid which can be used to generate heat and the chilled liquid has a variety of purposes such as drinking water and air conditioning purposes as well. Besides, Sharma et.al., [6] researched on two types of TEC systems, a single stage and multiple stage one, they found out that while the single one uses the same number of elements and have the same COP (coefficient of performance), the multiple stage one has a much higher peak [6]. Linking TEG (Thermoelectric generators) to TEC's would create a system with low operating power but low maximum cooling power as well since it would not be able to utilize $100 \%$ of the TEG's generated energy. In addition, Chan et al. [7] found that the hotter the surface on the TEG the higher the percentage reduction in COP and cooling power of the TEC. They say that the maximum cooling power would come from it being linked to a number of TEG's [7].

In this paper, a simple, mobile, and unique briefcase-shaped air cooler has been designed and developed. Since the literature on TEC based air cooling systems is limited and not commercially available because of low COP and design robustness; therefore, TEC technology has been considered and experimentally tested for the proposed briefcase-shaped air cooler. At first, a detailed description of the experimental set-up has been presented including component configuration and experimental procedure. Lastly, experimental results have been illustrated and calculated the COP of the system.

\section{Experimental Set-up, Configuration, and Procedure \\ 2.1. System Set-up and Configuration}

Figure 1(a) presents a schematic diagram of the proposed briefcase-shaped single outlet air cooling system. The proposed cooling system consists of two main subsystems i.e., one is the heat exchanger system (see Fig. 1(b)) and another one is the TEC system as shown in Fig. 1(c). The main components of the developed system are heat exchanger, fan, electric pump, water storage tank, TEC system, plexiglass acrylic sheets, liquid, connecting tubes insulating foams (see details in Table 1). K-type thermocouples with Omega 4-channel data logger were used in the experiment to measure the temperature at different points of interest. In this work, 2 different test environments were considered (e.g., one was a small room and another one was a comparatively big room (see details in Table 1), all walls are insulated).

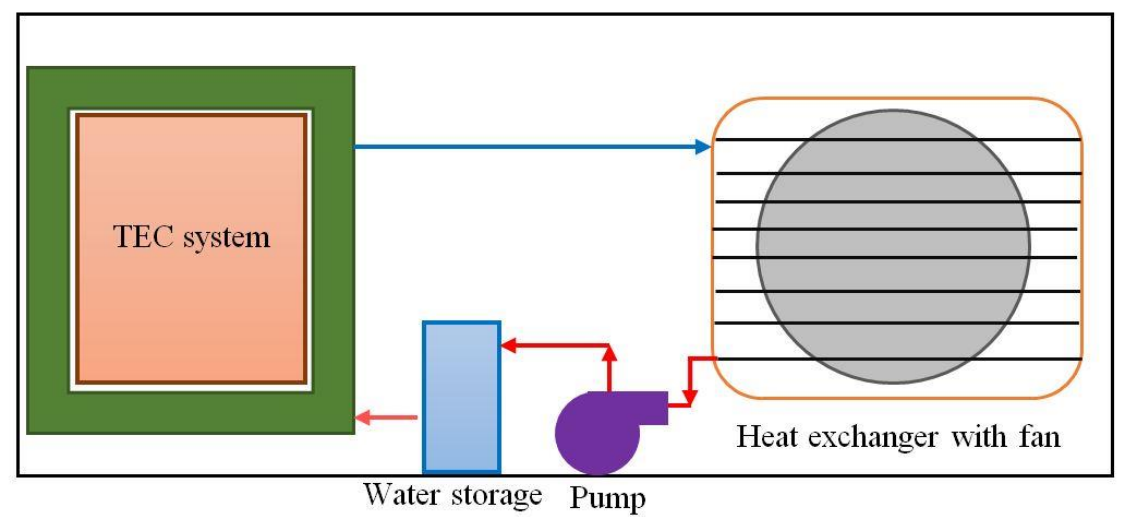

(a) 


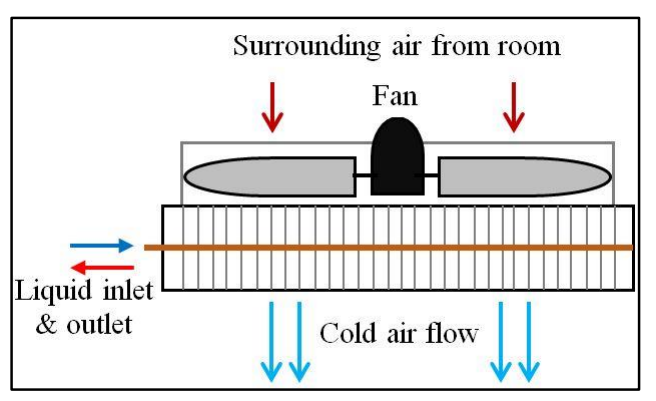

(b)

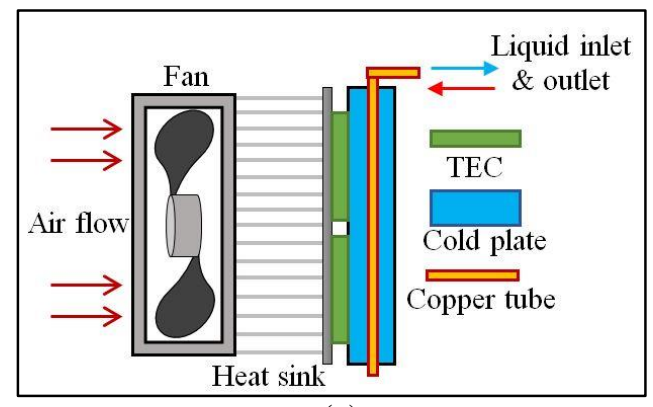

(c)

Fig. 1: (a) Schematic representation of the proposed single outlet briefcase-shaped air cooling system using TEC, (b) top view of the heat exchanger with fan, and (c) detailed presentation of the side view of the TEC system.

Table 1: List of components used in the proposed air cooling system.

\begin{tabular}{|c|c|c|}
\hline Components & Dimensions & Specifications \\
\hline Heat exchanger & $15 \mathrm{~cm} \times 15 \mathrm{~cm}$ & 6 channels and 10 channel; Aluminum alloy \\
\hline Fan & $12 \mathrm{~cm} \times 12 \mathrm{~cm}$ & DC12V 0.15A \\
\hline Electric pump & & $\begin{array}{c}\text { DC } 12 \mathrm{~V} \text {; Head: } 5 \mathrm{~m} \text {; Flow rate: } 500 \mathrm{~L} / \mathrm{hr} \\
\text { Power: } 13.2 \mathrm{~W}\end{array}$ \\
\hline Water storage tank & $8 \mathrm{~cm} \times 5 \mathrm{~cm} \times 5 \mathrm{~cm}$ & \\
\hline TEC liquid cooling system & $\begin{array}{c}\text { Fin: } 25 \mathrm{~cm} \times 8 \mathrm{~cm} \times 18 \mathrm{~cm} \\
\text { Fan: } 17 \mathrm{~cm} \times 17 \mathrm{~cm} \\
\text { Copper tube cold plate: } 25 \mathrm{~cm} \times 18 \mathrm{~cm} \times 1.5 \mathrm{~cm}\end{array}$ & $\begin{array}{c}\text { Copper tube cold plate: } 8 \text { channel } \\
\text { Weight: } 5.8 \mathrm{Kg} \\
\text { TE power: } 24 \mathrm{DC}, 17.3 \mathrm{~A} \\
\text { Fan: } 24 \mathrm{DC}, 1 \mathrm{~A}\end{array}$ \\
\hline Proposed system & $60 \mathrm{~cm} \times 23 \mathrm{~cm} \times 13 \mathrm{~cm}$ & $\begin{array}{l}\text { Material: plexiglass acrylic sheets } \\
\text { Weight: } 6.3 \mathrm{~kg}\end{array}$ \\
\hline Liquid & & $50 \%$ ethylene glycol and $50 \%$ water: 0.5 liter \\
\hline Small room & $60 \mathrm{~cm}^{3}$ & Styrofoam: wall thickness $-2.5 \mathrm{~cm}$ \\
\hline Large room & $100 \mathrm{~cm}^{3}$ & Wood: thickness $-1 \mathrm{~cm}$ \\
\hline Thermocouples & & K-type \\
\hline
\end{tabular}

\subsection{Experimental Procedure}

A picture of the developed system is shown in Fig 2. The experimental procedure with the Briefcase-shaped air cooling prototype was carried out on various levels with different scenarios to produce a variable amount of results. The TEC system was connected to a DC power source namely NI PS-17 power supply which was connected to the main supply. The TEC was insulated using fiber-glass insulation wool and then with insulation foam to make sure that no outside air could come near. A working fluid which consists of $50 \%$ ethylene glycol and $50 \%$ water was used in the system to cool down from the cold side of the TEC system. The set-up was developed to serve two purposes i.e., to cool the air of the room and (2) to be portable enough to carry/serve as a compact design compared to many other previous bulky designs of the thermoelectric air conditioning system. In order to figure out the temperature change through the entire system and find out various heat losses, K-type thermocouples were inserted at the inlets and outlets of the air, hot and cold sides of both the TEC and the heat exchanger. The performance of the system was checked by using a duct and creating a closedloop with two different heat exchangers, first the 6 channel radiator with heat changer and then a 10 channel radiator with a heat changer was tested to check which heat exchanger provides the most efficient transfer of heat from the surroundings into the liquid hence creating cold air. Later on, another test was performed using primarily the 6 channel heat exchanger in a small enclosed room of $60 \mathrm{~cm}^{3}$ at first without a heat source and then with a heat source. Lastly, the same experiment was conducted for a room size of $100 \mathrm{~cm}^{3}$ to receive a more evened out distribution of the heat change and test the performance of the system. In the experimental tests, for the 6-channel radiator the values are as follows. T1 represents output airflow 
temperature, T2 is input airflow temperature, T3 is TEC cold plate temperature, T4 ambient temperature, T5 is temperature for cold liquid from TEC, T6 is for hot liquid entering into TEC, T7 is the temperature of hot liquid coming out from the heat exchanger, and T8 is the cold liquid entering into the heat exchanger. On the other hand, for the 10-channel radiator the inputs are, T1 as the output airflow temperature, T2 as the ambient temperature, T3 as the TEC cold plate temperature, T4 as the temperature for the cold liquid from the TEC, T6 as the temperature of the corresponding hot liquid, T7 as the hot liquid exiting the heat exchanger, and T8 as the cold liquid going into the heat exchanger.

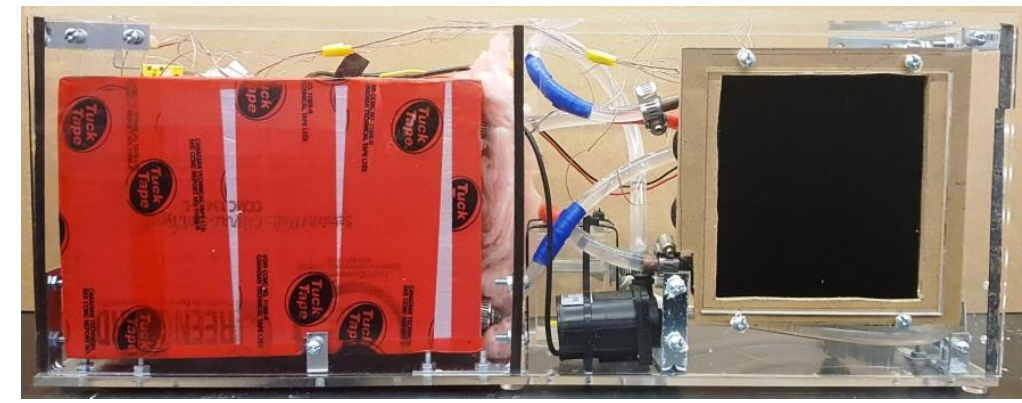

Fig. 2: Image of a developed TEC based air cooling system.

\section{Experimental Tests and Results}

Figures 3(a) and 3(b) show the experimental results tested on 6-channel and 10-channel based heat exchanger, respectively in order to compare their efficiency for the proposed air cooling system. At first, the 6-channel heat exchanger was tested and ran for 1 hour but it only took about 30 minutes for all the temperatures to reach a steady state. The result shows that the temperature of the output airflow drops around $3.5^{\circ} \mathrm{C}$. Then, the same experiment was performed using the 10-channel heat exchanger which results in reducing the temperature to $2{ }^{\circ} \mathrm{C}$ from inlet air temperature. Therefore, the 6channel based heat exchanger was used for the rest of the experiments in this study as it shows better performance than the 10-channel one.

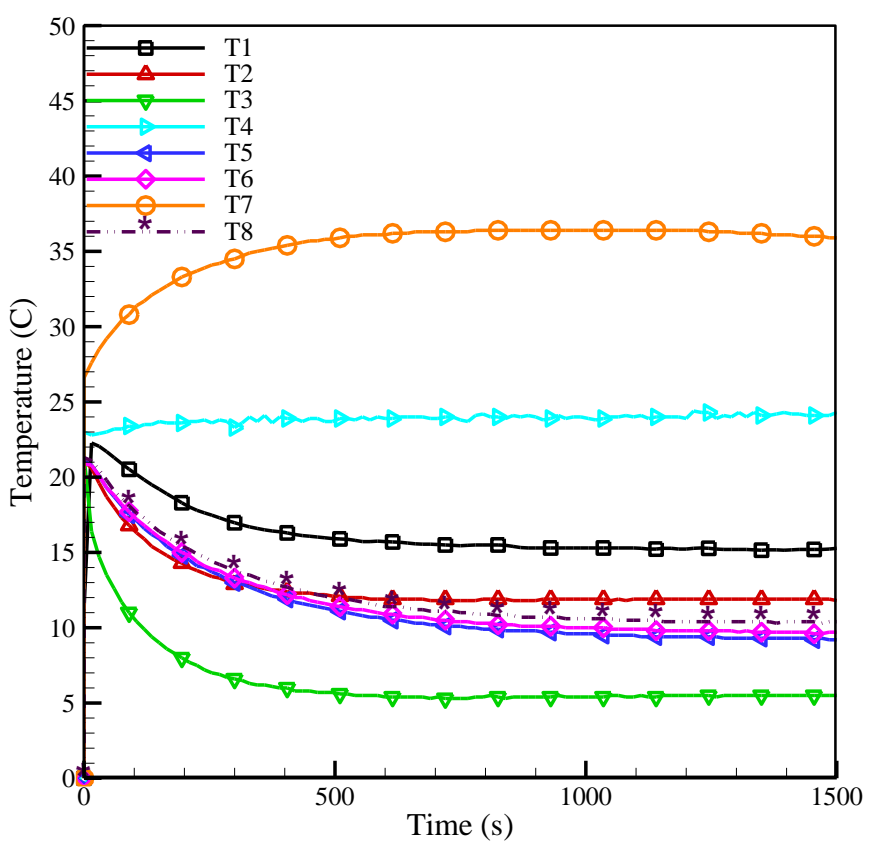

(a)

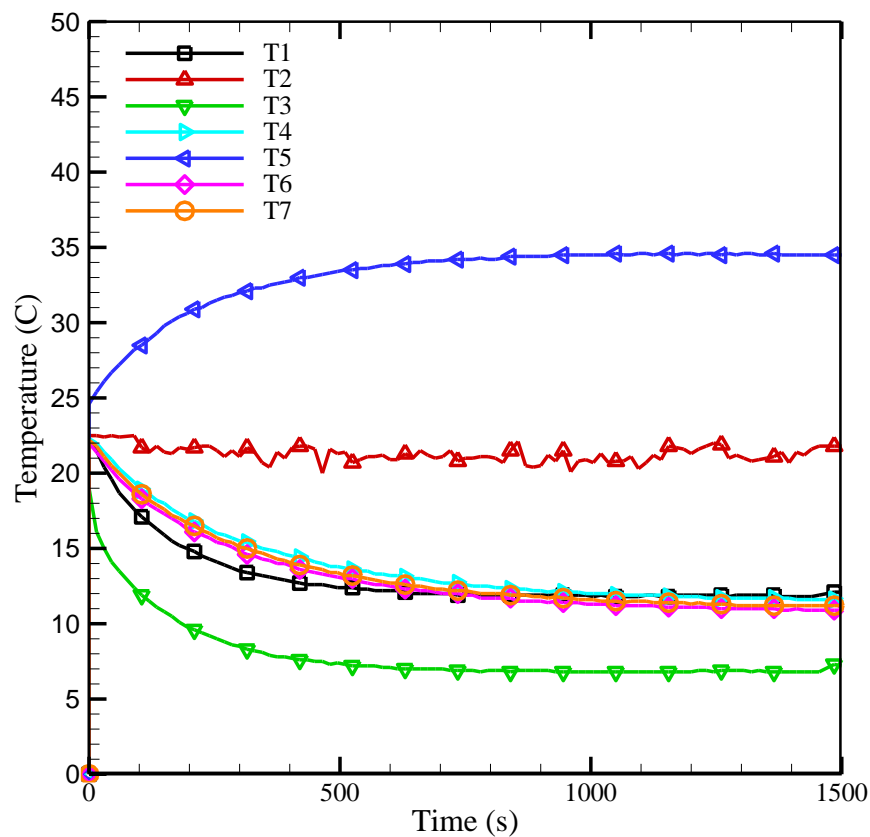

(b)

Fig. 3: (a) 6 channel radiator heat exchanger and (b) 10-channel heat exchanger with a fan. 
Figures 4(a) and 4(b) present a comparison between temperature profile along with time with and without a heat source, respectively while the experiment was performed in a small enclosed room $\left(60 \mathrm{~cm}^{3}\right)$. It can be noticed that the outlet air temperature reaches around $17^{\circ} \mathrm{C}$ which is around $5{ }^{\circ} \mathrm{C}$ less than ambient without a heat source $(100 \mathrm{~W}$ bulb) inside the closed room. In addition, this outlet temperature increases and remains steady at $22.5^{\circ} \mathrm{C}$ while using a heat source that has a surrounding temperature of $115^{\circ} \mathrm{C}$. Therefore, it can be said that the developed air cooling system is trying to keep the room temperature within the comfort level. By using a $100 \mathrm{~cm}^{3}$ room in size, it was then able to create an environment that would allow heat to dissipate effectively inside the room and spread the cold air coming out from our proposed system. The experimental results were plotted in Fig. 5. The room is made with wood and sealed off using wood bonding glue and an airtight scenario is created with foam sealant at all the edges and corners. Figure 5(a) shows that the proposed air cooling system keeps the large room temperature at $20^{\circ} \mathrm{C}$ without any heat source while this temperature remains the same using a heat source $(100 \mathrm{~W})$ as shown in Fig 5(b).

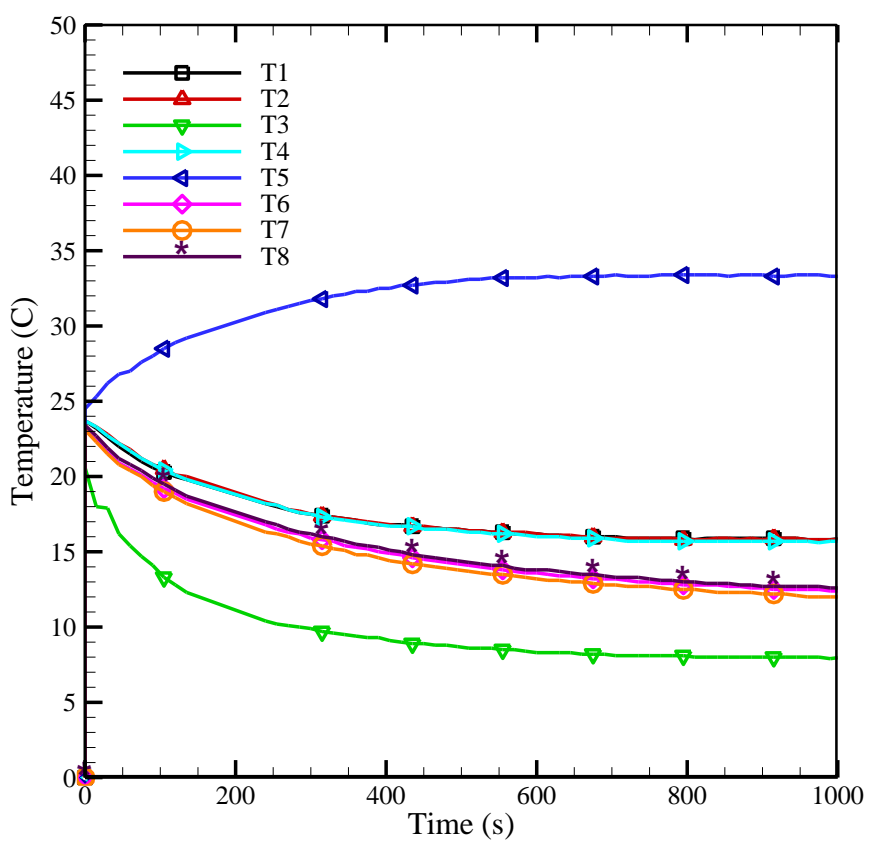

(a)

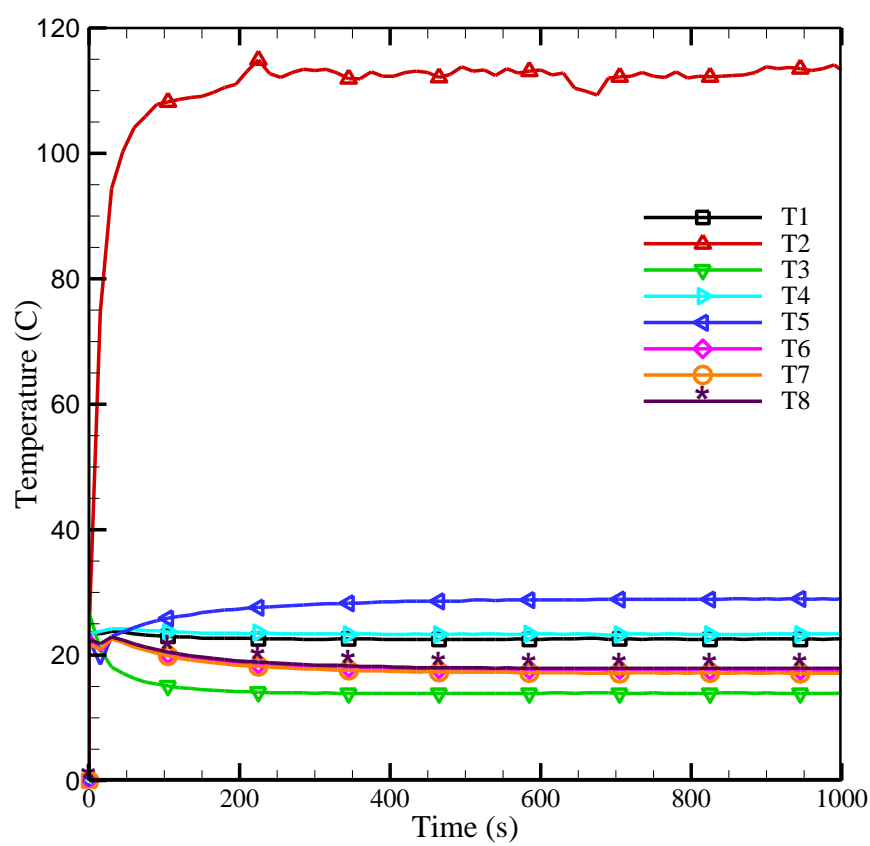

(b)

Fig. 4: (a) Closed small room temperature change without heat source. (b) Closed small room temperature analysis with a heat source $(100 \mathrm{~W})$. 


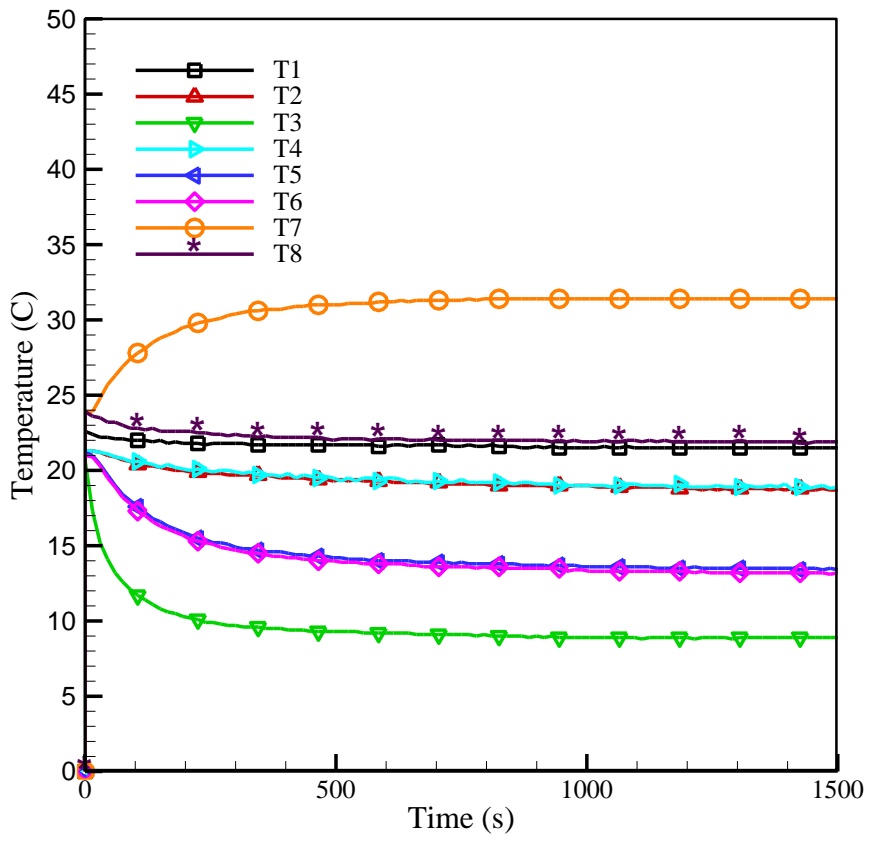

(a)

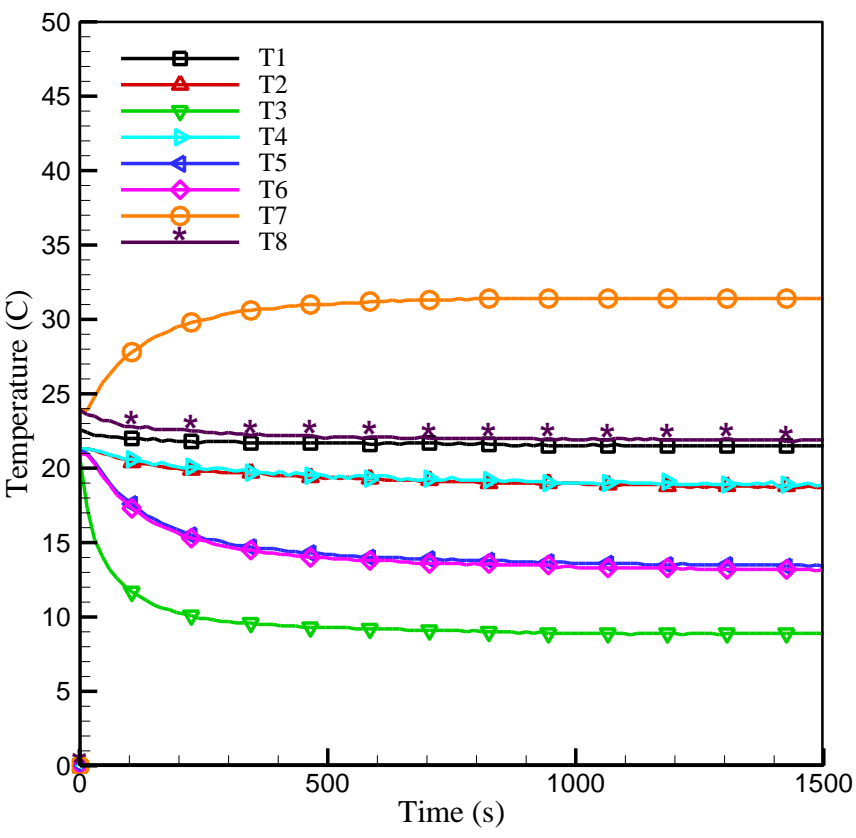

(b)

Fig. 5: (a) Large closed room temperature analysis without a heat source and (b) large closed room temperature analysis with a heat source $(100 \mathrm{~W})$.

\section{Coefficient of Performance and Uncertainty Analysis}

The coefficient of performance (COP) refers to the thermal efficiency of the system that defines the ration of heat transfer rate to the total power input to the system. Typical COP of a refrigeration system varies between 2 and 4 depending on the ambient temperature and power input to the system where power input is in $\mathrm{kW}$ range [8]. In order to calculate the COP of the proposed system, Eqs. (1) - (2) were used that came up to around 0.294.

$$
\begin{gathered}
\mathrm{COP}=\frac{\dot{Q_{L}}}{W_{\text {in }}} \\
\dot{Q_{L}}=\dot{m} C_{p} \Delta T
\end{gathered}
$$

where, $\dot{Q}_{L}$ is the heat removal rate, $W_{\text {in }}$ is the total power input to the system $(365 \mathrm{~W}), \dot{m}$ is the mass flow rate $(2.098$ $1 / \mathrm{min}), C_{P}$ is the specific heat of the fluid $\left(3.412 \mathrm{~kJ} / \mathrm{Kg}{ }^{\circ} \mathrm{C}\right)$, and $\Delta T$ is the temperature difference between hot and cold liquid of the heat exchanger $\left(T_{H}=14.8^{\circ} \mathrm{C}\right.$ and $\left.T_{C}=13.9^{\circ} \mathrm{C}\right)$. The COP of the proposed system is lower compared to the typical value; however, the total power input of the system that includes pump, fan, and TEC system is relatively low. A relative uncertainty of the system was also calculated and listed in Table 2 using the root-sum-square method (RSS) [9].

Table 2: Relative uncertainty calculation of the used sensors in the experiment.

\begin{tabular}{|l|l|l|l|}
\hline Sensor & Uncertainty, $\mathrm{U}(\%)$ & Measured value, $\mathrm{x}$ & Relative Uncertainty, (U/x) \% \\
\hline K-type thermocouple & $\pm 0.1\left[{ }^{\circ} \mathrm{C}\right]$ & $T_{H}=14.8^{\circ} \mathrm{C}$ & $T_{H}=T_{C}= \pm 0.007$ \\
& & $T_{C}=13.9^{\circ} \mathrm{C}$ & \\
\hline Multimeter & $\mathrm{V}= \pm 0.1(\mathrm{~V})$ & $\mathrm{V}=110 \mathrm{~V}$ & $\mathrm{~V}= \pm 0.001$ \\
& $\mathrm{I}= \pm 0.5(\mathrm{~A})$ & $\mathrm{I}=3.5 \mathrm{~A}$ & $\mathrm{I}= \pm 0.14$ \\
\hline
\end{tabular}




\section{Conclusion}

In this work, a unique briefcase-shaped air cooling system using thermoelectric cooling technology has been proposed. The proposed system is very simple to build and easy to carry anywhere in the room. The developed mobile air cooler is around $6.3 \mathrm{~kg}$ in weight. Here, detailed system descriptions and various performance tests have been presented. The developed air cooling system has been tested in open space and inside two different room sizes with and without a heat source. The best results are the ones shown with one $100 \mathrm{~W}$ bulb which mimics the heat produced by an average human inside the large room since there is enough space for the air to move around and be cooled by the TEC. The temperature is reduced from $24{ }^{\circ} \mathrm{C}$ to $20{ }^{\circ} \mathrm{C}$ which is a comfortable temperature for the human body. The calculated coefficient of performance of the proposed system is nearly 0.3 which requires only $365 \mathrm{~W}$ as electrical power input. The future work can be focused on using different working fluid which has a faster heat receiving and removing characteristics. In addition, the weight of the system can be also reduced by reducing the weight of the TEC system which will make the system more compact and handy.

\section{References}

[1] A. Allouhi, T. Kousksou, A. Jamil, P. Bruel, Y. Mourad, and Y. Zeraouli, Y. "Solar driven cooling systems: An updated review," Renewable and Sustainable Energy Reviews, vol. 44, pp. 159-181, 2015, doi:10.1016/j.rser.2014.12.014.

[2] I. Sarbu, "A comprehensive review of solar thermoelectric cooling systems," no. May, pp. 395-415, 2017.

[3] W. Pasut, H. Zhang, E. Arens, and Y. Zhai, "Energy-efficient comfort with a heated/cooled chair: Results from human subject tests," Building and Environment, vol. 84, pp. 10-21, 2015, doi:10.1016/j.buildenv.2014.10.026

[4] K. Irshad, K. Habib, F. Basrawi, N. Thirumalaiswamy, R. Saidur, and B.B. Saha, "Thermal comfort study of a building equipped with thermoelectric air duct system for tropical climate," Applied Thermal Engineering, vol. 91, pp. 1141-1155, 2015. doi:10.1016/j.applthermaleng.2015.08.077

[5] Y. Alomair, M. Alomair, S. Mahmud, and H.A. Abdullah, "Theoretical and experimental analyses of solarthermoelectric liquid-chiller system," International Journal of Refrigeration, vol. 56, pp.126-139, 2015. doi:10.1016/j.ijrefrig.2015.01.003.

[6] S. Sharma, V. Dwivedi, V, and S. Pandit, "Exergy analysis of single-stage and multi stage thermoelectric cooler," International Journal of Energy Research, vol. 38(2), pp. 213-222, 2013. doi:10.1002/er.3043.

[7] W. Chen, C. Wang, and C. Hung, "Geometric effect on cooling power and performance of an integrated thermoelectric generation-cooling system," Energy Conversion and Management, vol. 87, pp. 566-575, 2014.

[8] COPs, EERs, and SEERs, https://www.powerknot.com/2011/03/01/cops-eers-and-seers/, [accessed: November 25, 2019].

[9] R. J. Moffat, “Describing the uncertainties in experimental results," Exp. Therm. Fluid Sci., 1988. 